\title{
Metformin inhibits leptin secretion via a mitogen-activated protein kinase signalling pathway in brown adipocytes
}

\author{
Johannes Klein ${ }^{*}$, Sören Westphal ${ }^{*}$, Daniel Kraus, Britta Meier, \\ Nina Perwitz, Volker Ott, Mathias Fasshauer ${ }^{1}$ and \\ H Harald Klein ${ }^{2}$ \\ Department of Internal Medicine I, University of Lübeck, Ratzeburger Allee 160, 23538 Lübeck, Germany \\ ${ }^{1}$ Department of Internal Medicine III, University of Leipzig, Germany \\ ${ }^{2}$ Department of Medicine 1, Kliniken Bergmannsheil, Ruhr-University Bochum, Germany \\ (Requests for offprints should be addressed to J Klein; Email: j.klein@uni-luebeck.de) \\ (*J Klein and S Westphal contributed equally to this work)
}

\begin{abstract}
Metformin is an anti-diabetic drug with anorexigenic properties. The precise cellular mechanisms of its action are not entirely understood. Adipose tissue has recently been recognized as an important endocrine organ that is pivotal for the regulation of insulin resistance and energy homeostasis. Due to its thermogenic capacity brown adipose tissue contributes to the regulation of energy metabolism and is an attractive target tissue for pharmacological approaches to treating insulin resistance and obesity. Leptin is the prototypic adipocyte-derived hormone inducing a negative energy balance. We investigated effects of metformin on adipocyte metabolism, signalling, and leptin secretion in a brown adipocyte model. Metformin acutely stimulated p44/p42 mitogenactivated protein (MAP) kinase in a dose- $(3 \cdot 2$-fold at $1 \mathrm{mmol} / 1, P<0 \cdot 05)$ as well as time-dependent $(3 \cdot 8$-fold at 5 min, $P<0 \cdot 05)$ manner. This stimulation was highly selective since phosphorylation of intermediates in the stress kinase, janus kinase (JAK)-signal transducer and
\end{abstract}

activator of transcription (STAT), and phosphatidylinositol (PI) 3-kinase signalling pathways such as p38 MAP kinase, STAT3, and Akt was unaltered. Furthermore, chronic metformin treatment for 12 days dose-dependently inhibited leptin secretion by $35 \%$ and $75 \%$ at $500 \mu \mathrm{mol} / 1$ and $1 \mathrm{mmol} / 1 \mathrm{metformin}$ respectively $(P<0 \cdot 01)$. This reduction was not caused by alterations in adipocyte differentiation. Moreover, the impairment in leptin secretion by metformin was reversible within $48 \mathrm{~h}$ after removal of the drug. Pharmacological inhibition of p44/p42 MAP kinase prevented the metformin-induced negative effect on leptin secretion. Taken together, our data demonstrate direct acute effects of metformin on adipocyte signalling and endocrine function with robust inhibition of leptin secretion. They suggest a selective molecular mechanism that may contribute to the anorexigenic effect of this antidiabetic compound.

Journal of Endocrinology (2004) 183, 299-307

\section{Introduction}

Metformin is a widely used anti-diabetic agent for the treatment of type 2 diabetes. It enhances insulin sensitivity. Furthermore, this compound displays the unique characteristic of promoting weight loss and reducing appetite (Bailey \& Turner 1996, Matthaei et al. 2000, Kirpichnikov et al. 2002). Although used as a drug since the late 1950s, the mechanisms of action by which metformin lowers glucose and lipid levels remain unclear.

Potential direct effects of metformin on signalling pathways are poorly understood. In muscle, insulin receptor tyrosine kinase activity (Stith et al. 1996, 1998) and recruitment of glucose transporter (GLUT) 4 to the plasma membrane (Sarabia et al. 1992, Rouru et al. 1995) have been shown to be increased by chronic metformin treatment. In hepatocytes metformin inhibits gluconeogenesis and glycogenolysis probably due to a number of mechanisms such as diminished lactate uptake (Radziuk et al. 1997), reduction in pyruvate carboxylase-phosphoenolpyruvate carboxykinase activity (Large \& Beylot 1999), antagonism to glucagon (Dominguez et al. 1996), enhancement of insulin action (Wiernsperger \& Bailey 1999), and decreased concentrations of adenosine triphosphate (Argaud et al. 1993). In this context, modulation of cellular respiration via unidentified cell-signalling pathways appears to play a role (Dominguez et al. 1996, Yki-Jarvinen et al. 1999, Kirpichnikov et al. 2002). Activation of 5'-AMPactivated protein kinase (AMPK) has been implicated in metformin action in hepatocytes (Zhou et al. 2001). 


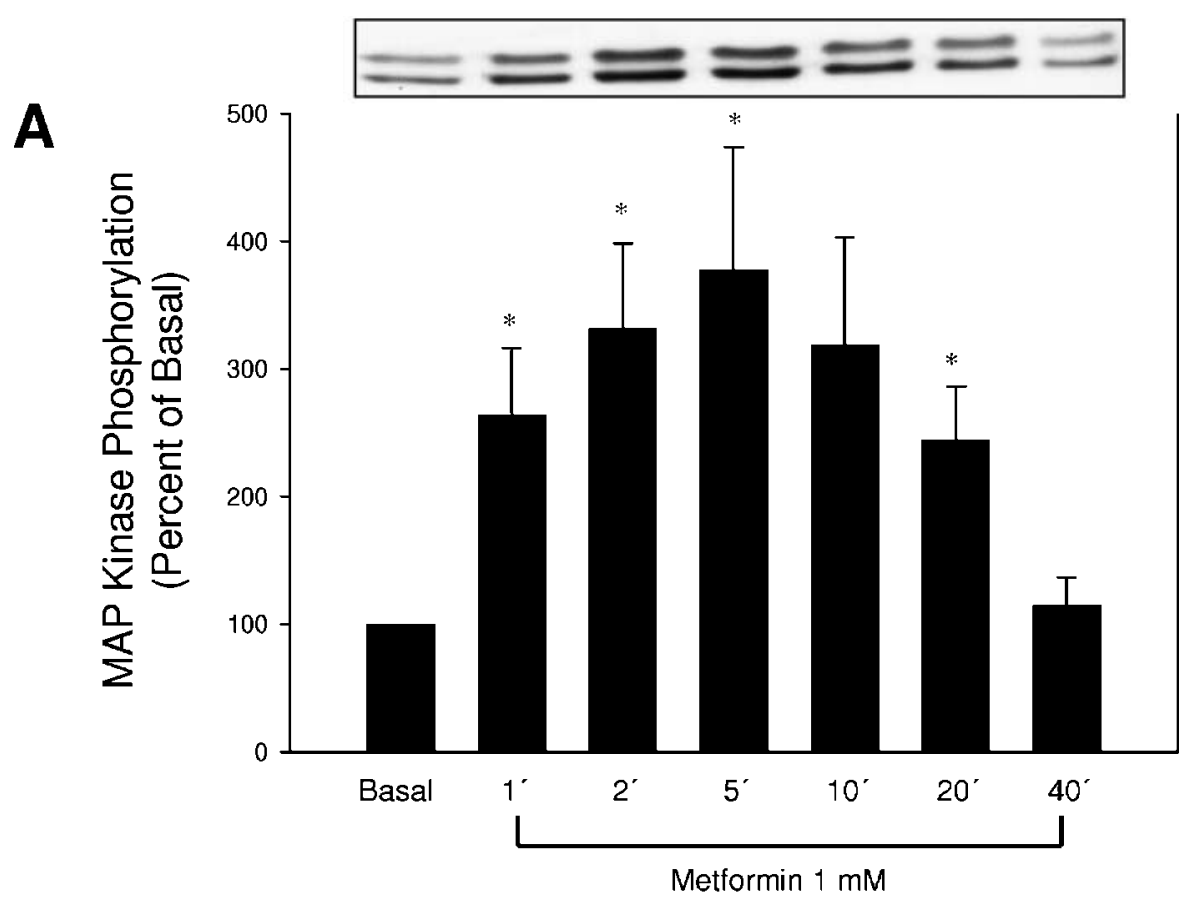

B

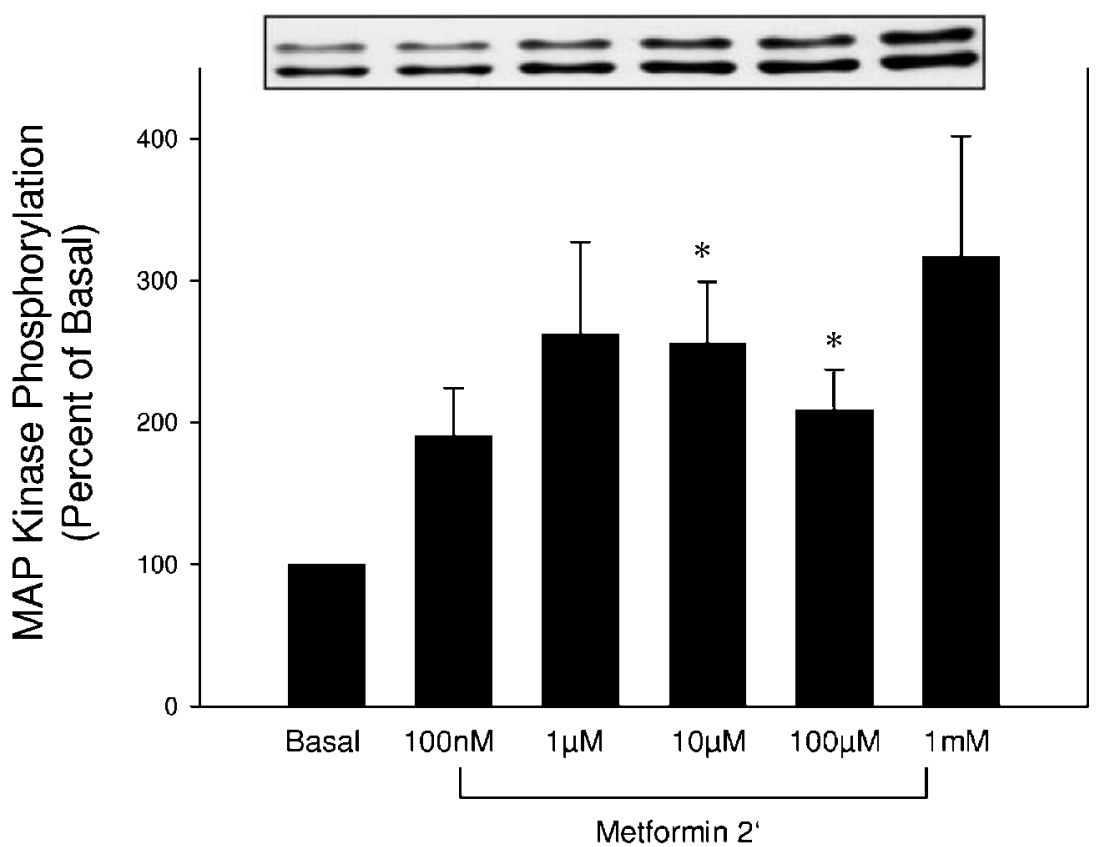

Figure 1 Metformin acutely activates p44/p42 MAP kinase. Fully differentiated brown adipocytes were stimulated with metformin for the times $(1-40 \mathrm{~min})(\mathrm{A})$ and at the concentrations $(B)$ indicated. (A) Cell lysates and immunoblots using phospho-specific antibodies were prepared as described in Materials and Methods. (B) Bar graph analyses with S.E.M. of $\geq 6$ independent experiments and representative immunoblots are shown. * Denotes statistically significant $(P<0 \cdot 05)$ differences comparing non-treated (Basal) to metformin-treated cells. 
By contrast to liver and muscle, relatively little is known about direct metformin actions in adipocytes. In rat adipose tissue glucose uptake has been found to be enhanced (Matthaei et al. 1991, 1993) whereas in human adipocytes no change has been described by metformin treatment (Pedersen et al. 1989, Ciaraldi et al. 2002). Recently, there has been a growing appreciation of adipose tissue as an endocrine organ that is pivotal for the systemic regulation of insulin action and energy homeostasis (Rajala \& Scherer 2003). Direct interactions of metformin with adipocyte signalling and endocrine function may thus be instrumental for this compound's effects. Clinical studies with metformin have constantly shown either a decrease in body weight (DeFronzo et al. 1991, DeFronzo \& Goodman 1995) or at least a significantly smaller increase in body weight compared with other forms of treatment (Yki-Jarvinen et al. 1999). The adipocyte-derived hormone, leptin, is an essential player in regulating energy homeostasis (Friedman \& Halaas 1998, Spiegelman \& Flier 2001, Friedman 2002). Brown adipose tissue importantly contributes to the modulation of energy homeostasis in rodents (Lowell \& Flier 1997, Lowell \& Bachman 2003), has been implicated in human obesity (Fumeron et al. 1996, Oberkofler et al. 1997, Fogelholm et al. 1998, Valve et al. 1998), and is an attractive target tissue for pharmacotherapeutic approaches to obesity (Danforth \& Himms-Hagen 1997, Lowell \& Flier 1997, Bray \& Greenway 1999, Tiraby et al. 2003, Klaus 2004). Recent studies suggest the existence of a basal brown adipose phenotype that may be important for the maintenance of normal insulin sensitivity and energy homeostasis (Yang et al. 2003). Moreover, transdifferentiation of white to brown adipocytes has been demonstrated and may offer interesting new therapeutic perspectives for treating insulin resistance and energy balance disorders (Tiraby \& Langin 2003, Tiraby et al. 2003). We have previously demonstrated robust leptin secretion in brown adipocytes (Klein et al. 2002, Kraus et al. 2002). Investigation of direct metformin interaction with adipose tissue may identify molecular targets and provide insights into mechanisms of insulin resistance and energy homeostasis regulation.

Here, we studied direct metformin effects on adipocyte signalling, differentiation, and leptin secretion (Klein et al. 2002, Kraus et al. 2002). We demonstrate a selective activation of $\mathrm{p} 44 / \mathrm{p} 42$ mitogen-activated protein (MAP) kinase by metformin and a differentiation-independent, robust reduction in leptin secretion that is prevented by pharmacological inhibition of p44/p42 MAP kinase.

\section{Materials and Methods}

\section{Materials}

Antibodies against the following molecules were employed for immunoblotting: signal transducer and activator of

\section{phospho-p38 MAP kinase}

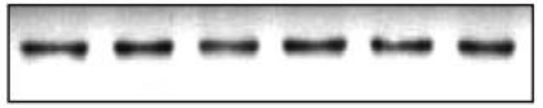

phospho-Akt

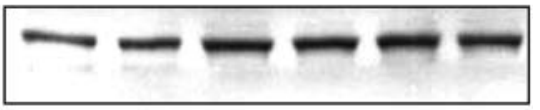

phospho-STAT3

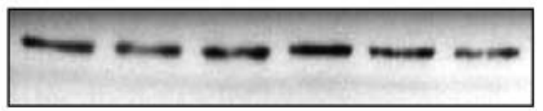

Basal

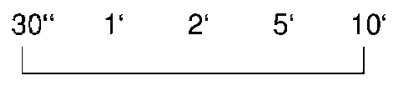

Metformin $1 \mathrm{mM}$

Figure 2 Metformin does not stimulate p38 MAP kinase, Akt or STAT3 phosphorylation. Adipocytes were stimulated with metformin $(1 \mathrm{mM})$ for the indicated times (30 s and 1, 2, 5 and $10 \mathrm{~min}$ ). Cell lysates and immunoblots using phospho-specific antibodies were prepared as described in Materials and Methods. Representative blots of phospho-p38 MAP kinase (upper panel), phospho-Akt (middle panel), and phospho-STAT3 (lower panel) of $\geq 5$ independent experiments are shown.

transcription (STAT) 3 (phospho-Tyr705), p44/p42 MAP kinase (phospo-Thr202/Tyr204), Akt (phospho-Ser473) (Cell Signaling Technology, Inc., Beverly, MA, USA), CCAAT enhancer binding protein (C/EBP) $\alpha$, peroxisome proliferator-activated receptor (PPAR) $\gamma$ (Santa Cruz Biotechnology, Inc., Santa Cruz, CA, USA), uncoupling protein (UCP)-1 (Alpha Diagnostic International, San Antonio, TX, USA). The pharmacological MAP kinase inhibitor, PD98059, was purchased from Cell Signaling Technology, Inc. Unless stated otherwise, all other chemicals were purchased from Sigma-Aldrich Co. (St Louis, MO, USA).

\section{Cell culture}

SV40T-immortalized brown adipocytes from the FVB strain of mice - generated as described elsewhere (Klein et al. 1999) - were used for all experiments. Preadipocytes were seeded on tissue culture plates (Sarstedt, Nümbrecht, Germany) and grown to confluence in culture medium with Dulbecco's modified Eagle's medium (Life Technologies, Paisley, Strathclyde, UK), supplemented with $20 \%$ fetal bovine serum, $4.5 \mathrm{~g} / 1$ glucose, $20 \mathrm{nM}$ insulin, $1 \mathrm{nM}$ triiodothyronine ('differentiation medium'), and penicillin/streptomycin. Adipocyte differentiation was induced by complementing the medium further with $250 \mu \mathrm{M}$ indomethacin, $500 \mu \mathrm{M}$ isobutylmethylxanthine and $2 \mu \mathrm{g} / \mathrm{ml}$ dexamethasone for $24 \mathrm{~h}$ when confluence was reached. After this induction period, cells were changed back to differentiation medium. Cell culture was continued for 5 more days before cells were starved for $24 \mathrm{~h}$ with serum-free medium prior to carrying out the 


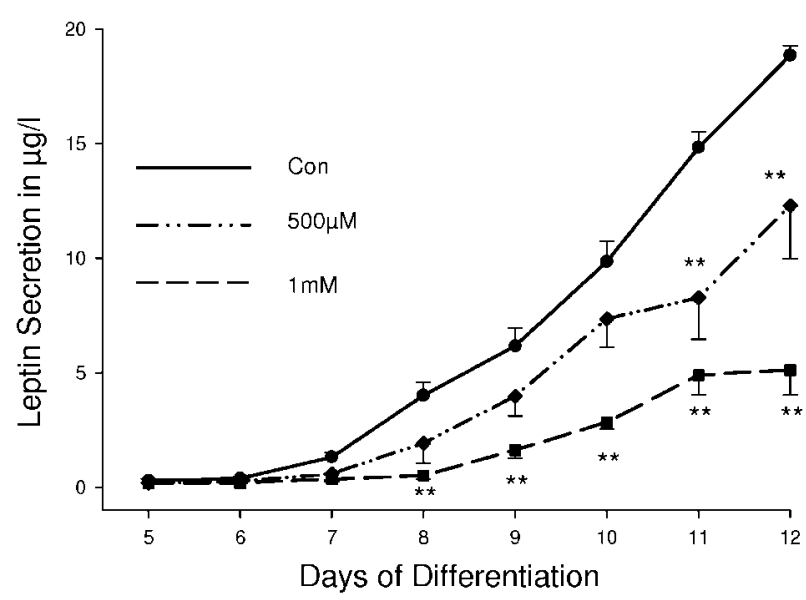

Figure 3 Chronic metformin treatment dose-dependently inhibits leptin secretion. Cells were chronically exposed to the indicated concentrations of metformin over the entire differentiation course. Medium was collected every $24 \mathrm{~h}$. Secretion of leptin was analysed in the culture medium using a mouse leptin RIA. A line graph with S.E.M. of $\geq 3$ independent experiments is shown comparing untreated cells $($ Con, $\bullet$ ) with $500 \mu \mathrm{M}(\diamond)$ and $1 \mathrm{mM}$ $(\boldsymbol{\square})$ metformin treatment. ${ }^{* *}$ Denotes high statistical significance $(P<0 \cdot 01)$.

immunoblotting experiments. For leptin secretion experiments, cell culture was continued for up to 9 days after induction of differentiation.

\section{Determination of leptin secretion}

Cells were chronically treated with or without metformin and medium was collected every $24 \mathrm{~h}$ from day 4 to day 12 of the differentiation course. Treatment with the pharmacological MAP kinase inhibitor, PD98059, was begun $30 \mathrm{~min}$ prior to adding metformin. The amount of leptin released into the medium was determined using a mouse leptin RIA (Linco Research, Inc., St Louis, MO, USA).

\section{Oil Red O staining}

Tissue culture plates were washed twice with PBS and fixed with $10 \%$ formalin for at least $1 \mathrm{~h}$ at room temperature. Cells were then stained for $1 \mathrm{~h}$ at room temperature with a filtered Oil Red $\mathrm{O}$ solution $(0.5 \mathrm{~g}$ Oil Red $\mathrm{O}$ in $100 \mathrm{ml}$ isopropyl alcohol). The staining solution was washed off the cells with distilled water twice.

\section{Western blotting}

SV40T-immortalized mouse brown adipocytes were used between passages 10 and 25 . For p44/p42 MAP kinase, Akt, p38 MAP kinase, and STAT3 analysis fully differentiated cells were starved for $24 \mathrm{~h}$ in serum-free medium prior to carrying out the experiments. Following treatment with metformin as indicated, proteins were isolated using whole cell lysis buffer containing $2 \mathrm{mM}$ vanadate, $10 \mu \mathrm{g} / \mathrm{ml}$ aprotinin, $10 \mu \mathrm{g} / \mathrm{ml}$ leupeptin, and $2 \mathrm{mM}$ PMSF. Protein content of lysates was determined by the Bradford method using the dye from Bio-Rad (Hercules, CA, USA). Lysates were submitted to SDS-PAGE and transferred to nitrocellulose membranes (Schleicher and Schuell Inc., Keane, NH, USA). Membranes were blocked with rinsing buffer $(10 \mathrm{mM}$ Tris, $150 \mathrm{mM} \mathrm{NaCl}$, $0.05 \%$ Tween, $\mathrm{pH} 7 \cdot 2$ ) containing $3 \%$ bovine serum albumin ('blocking solution') overnight. Membranes were then incubated in blocking solution for 1-2 $\mathrm{h}$ with the antibodies indicated. Protein bands were visualized using the chemiluminescence kit from Roche Molecular Biochemicals (Mannheim, Germany) and enhanced chemiluminescence films (Amersham Pharmacia Biotech, Freiburg, Germany).

\section{Statistical analysis}

Data are presented as means \pm S.E.M. Sigma Plot software (SPSS Science; Chicago, IL, USA) was employed for statistical analysis of all data. Statistical significance was determined using the unpaired Student's $t$-test. $P$ values $<0.05$ are considered significant, $<0.01$ highly significant.

\section{Results}

Metformin acutely induces $p 44 / p 42$ MAP kinase but not $p 38$ MAP kinase, Akt and STAT3 phosphorylation

$\mathrm{P} 44 / 42$ MAP kinase is an important signalling intermediate of growth factor signalling pathways and a major regulator of gene transcription. Treatment of fully differentiated brown adipocytes with metformin resulted in a time- and dose-dependent stimulation of $\mathrm{p} 44 / \mathrm{p} 42 \mathrm{MAP}$ kinase as assessed using phospho-specific antibodies (Fig. $1 \mathrm{~A}$ and $\mathrm{B})$. Metformin-induced activation was most prominent after 5 min (Fig. 1A) with a maximal 3.5-fold phosphorylation increase at a concentration of $1 \mathrm{mM}$ (Fig. 1B). There was no change in protein amounts of MAP kinase as assessed by immunoblots using p44/p42 MAP kinase antibodies (data not shown). Furthermore, metformin treatment did not induce significant changes in phosphorylation of p38 MAP kinase, Akt and STAT3 key signalling molecules of the stress kinase, phosphatidylinositol 3-kinase (PI 3-kinase), and janus kinase (JAK)/ STAT signalling pathways respectively (Fig. 2).

\section{Metformin treatment inhibits leptin secretion in a dose-dependent manner}

When cells were chronically exposed to metformin, there was a dose-dependent impairment in leptin secretion. Non-treated control cells displayed a differentiationdependent increase in leptin secretion over two orders of 


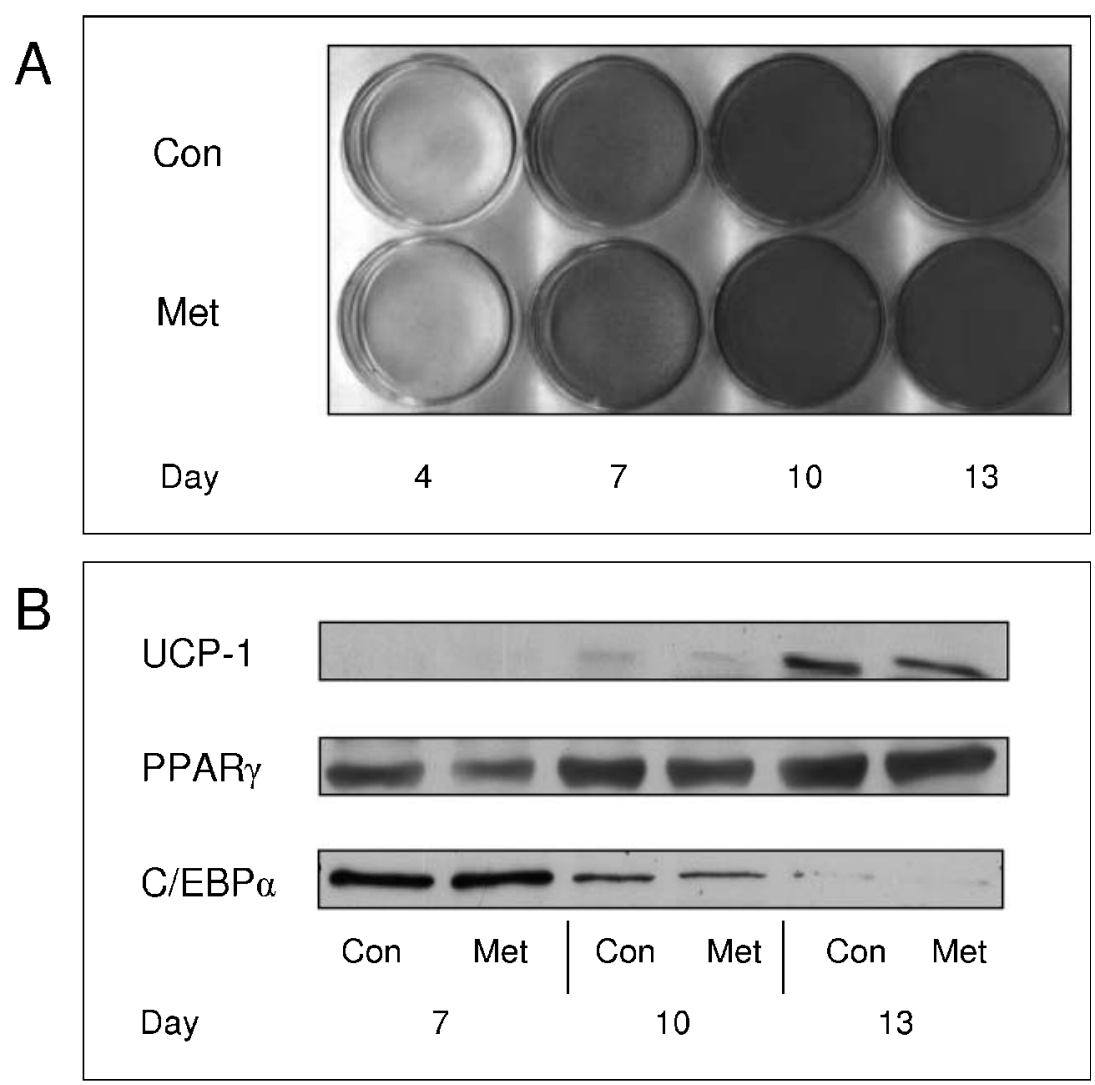

Figure 4 The inhibitory effect of metformin on leptin secretion is not caused by alterations in adipocyte differentiation. (A) Differentiation was assessed in cell lines either non-treated (Con) or chronically exposed to metformin (Met, $1 \mathrm{mM}$ ) using the fat-specific Oil Red O staining. (B) Using specific antibodies as applicable, protein expression of the differentiation markers uncoupling protein-1 (UCP-1, upper panel), peroxisome proliferator-activated receptor gamma (PPAR $\gamma$, middle panel) and CCAAT

enhancer-binding protein alpha ( $\mathrm{C} / \mathrm{EBP} \alpha$, lower panel) was analysed in immunoblots. Representative blots and staining results of $\geq 2$ independent experiments are shown.

magnitude with the lowest detectable leptin levels at a concentration of $0 \cdot 2 \mu \mathrm{g} / 1$ rising to the maximum detectable level of $20 \mu \mathrm{g} / 1$ during a 12-day-differentiation course (Fig. 3). Chronic metformin treatment dose-dependently inhibited this increase in leptin secretion with a maximum reduction of $35 \%$ and $75 \%$ at the end of the differentation course at concentrations of $500 \mu \mathrm{M}$ and $1 \mathrm{mM}$ metformin respectively. These changes were highly significant (Fig. 3). A significant inhibition of leptin secretion was also seen at $100 \mu \mathrm{M}$ metformin (data not shown). Furthermore, metformin did not influence glucose utilization and lactate production (data not shown).

The inhibitory effect of metformin on leptin secretion is not caused by alterations in differentiation

To separate the impairment in leptin secretion from a differentiation-dependent effect, we next investigated adipocyte differentiation under chronic metformin treat- ment. When differentiating adipocytes were stained with the fat-specific Oil Red $O$ at days 4, 7, 10 and 13 of the differentiation course there was no difference between metformin-treated and non-treated control cells (Fig. 4A). Furthermore, protein expression of early and late adipocyte differentiation markers such as $\mathrm{C} / \mathrm{EBP} \alpha, \operatorname{PPAR} \gamma$, and UCP-1 did not differ between metformin-treated and non-treated control cells throughout the differentiation course (Fig. 4B).

Subacute metformin treatment induces a reversible impairment in leptin secretion

To further define the kinetics of the inhibitory metformin effect on leptin secretion, we pretreated adipocytes for various periods of time with $1 \mathrm{mM}$ metformin on day 8 of the differentiation course, collected the medium every $24 \mathrm{~h}$, and continued cell culture for two more days without metformin exposure. Interestingly, metformin 


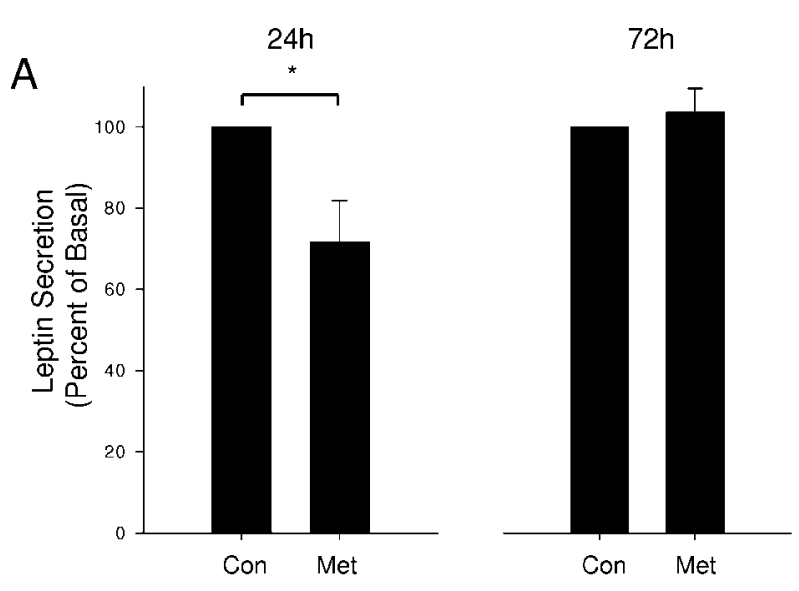

$\mathrm{B}$

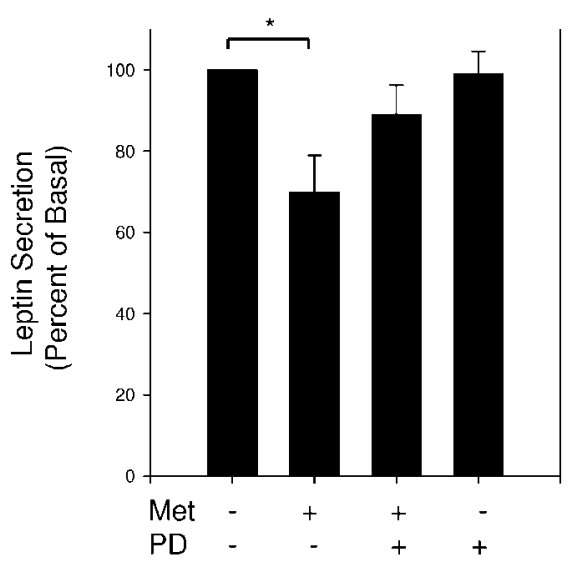

Figure 5 Subacute metformin treatment induces an impairment in leptin secretion that can be prevented by inhibition of $\mathrm{p} 44 / \mathrm{p} 42$ MAP kinase. On day 8 of the differentiation course cells were either left untreated (Con) or treated with metformin (Met, $1 \mathrm{mM}$ ) for $24 \mathrm{~h}$. Medium was collected $24 \mathrm{~h}$ (A, left panel) or $72 \mathrm{~h}$ (A, right panel) after removal of metformin. (B) The MAP kinase inhibitor, PD98059 (PD, $50 \mu \mathrm{M})$, was added $1 \mathrm{~h}$ prior to metformin treatment for $24 \mathrm{~h}$, and the medium was analysed for leptin concentrations $24 \mathrm{~h}$ later. A bar graph analysis with S.E.M. of $\geq 5$ independent experiments is shown. * Denotes statistical significance $(P<0 \cdot 05)$.

treatment for $24 \mathrm{~h}$ resulted in a significant $30 \%$ reduction of leptin secretion within the next $24 \mathrm{~h}$ (Fig. 5A, left panel). This effect was completely reversible $72 \mathrm{~h}$ after metformin removal from the medium (Fig. 5A, right panel). Furthermore, there was a time-dependent trend towards impaired leptin secretion after 8 and $16 \mathrm{~h}$ of metformin treatment whereas shorter periods of time did not show significant alterations in leptin secretion as compared with control cells (data not shown).

\section{Inhibition of $444 / p 42$ MAP kinase prevents the inhibitory metformin effect}

The impairment of leptin secretion by subacute metformin treatment in concert with the acute induction of $\mathrm{p} 44 / \mathrm{p} 42$
MAP kinase phosphorylation suggested an involvement of this signalling intermediate in the mediation of this effect. Metformin treatment for $24 \mathrm{~h}$ again significantly diminished leptin secretion by $30 \%$ on the following day as compared with non-treated control cells (Fig. 5B). However, when cells were pretreated with the p44/p2 MAP kinase inhibitor, PD98059, exposure to metformin failed to significantly inhibit leptin secretion (Fig. 5B). Treatment with the pharmacological inhibitor alone did not change basal leptin secretion (Fig. 5B).

\section{Discussion}

In this study, we show direct effects of the anorexigenic anti-diabetic drug, metformin, on adipocyte signalling and endocrine function with robust inhibition of leptin secretion.

Metformin directly induced p44/p42 MAP kinase activation. To our knowledge, this is the first report demonstrating stimulation of this important growth factor signalling intermediate by metformin. Apart from p44/ p42 MAP kinase, only AMPK and p38 MAP kinase have been shown to be implicated in intracellular metformin action so far. Zhou et al. (2001) and Hawley et al. (2002) described activation of AMPK by chronic treatment with metformin in rat hepatocytes and skeletal muscle. In skeletal muscle, Kumar \& Dey (2002) also found an increase in p38 MAP kinase activity by metformin. Interestingly, however, p38 stress kinase-, PI 3-kinase-, and JAK/STAT-signalling pathways remained unaffected by metformin treatment in our study using adipocytes. These discrepancies may indicate tissue- and cell-specific effects of metformin.

Of note, stimulation of $\mathrm{p} 44 / \mathrm{p} 42$ MAP kinase occurred acutely and was time- and dose-dependent. In concert with the demonstrated selectivity of action, these findings suggest a receptor-mediated signalling mechanism employed by metformin in adipocytes. However, no specific receptor mediating the effects of metformin has been identified so far. Rather, this lipophilic compound may exert its effects by alterations of the cellular membrane structure (Meuillet et al. 1999).

Activation of $\mathrm{p} 44 / \mathrm{p} 42$ MAP kinase plays an important role in regulating gene expression, insulin signalling and specifically in brown adipocytes - thermogenesis (Porras et al. 1998, Klein et al. 2000). Therefore, it appears plausible to propose important functional consequences of metformin-induced acute changes in p44/p42 MAP kinase signalling in adipocytes. Indeed, we found that metformin directly affected endocrine function and inhibited leptin secretion. We used a previously well characterised adipocyte model (Klein et al. 2002) that displays strong leptin secretion (Kraus et al. 2002). A decrease in leptin levels in metformin-treated individuals has been found in several studies (Freemark \& Bursey 2001, 


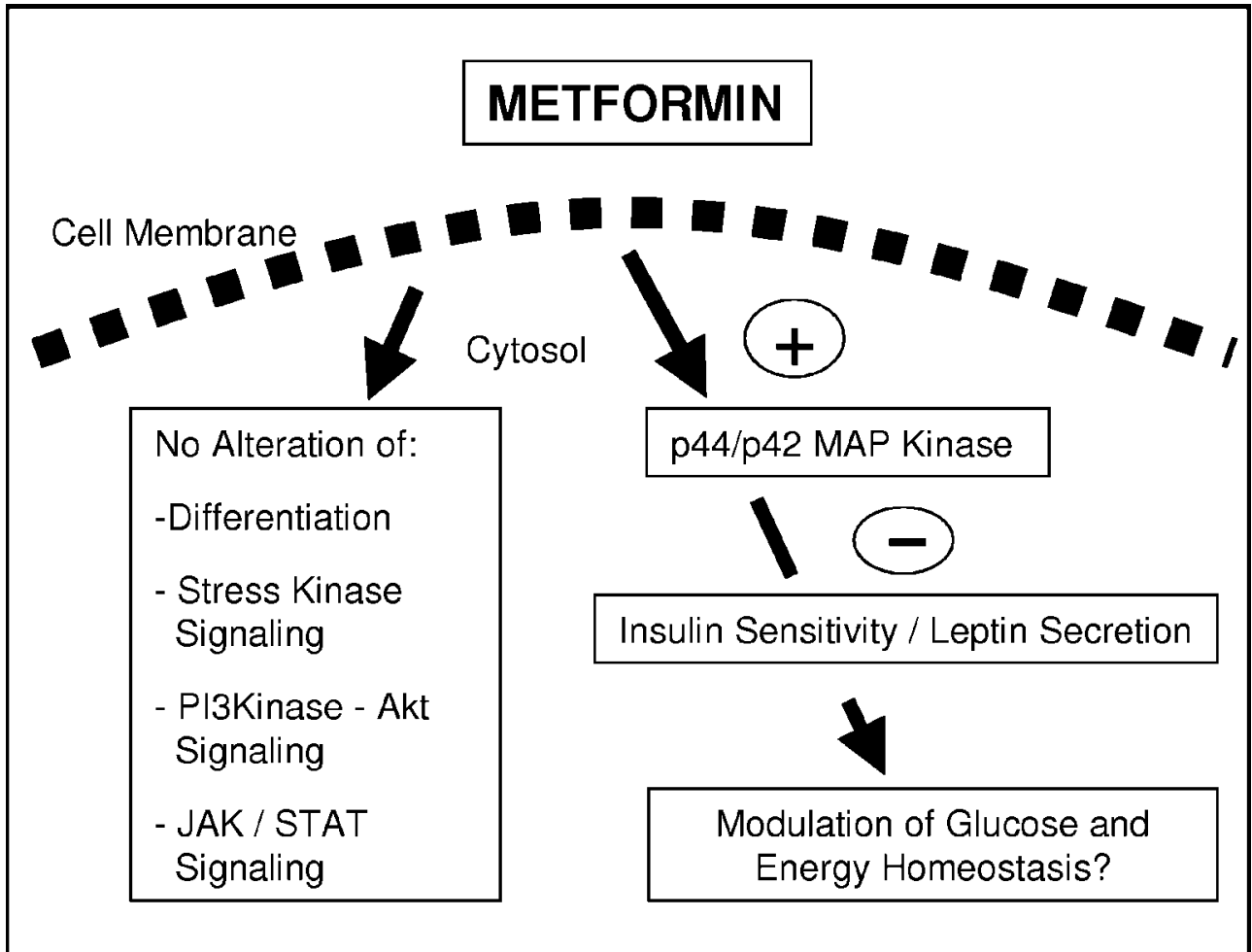

Figure 6 Metformin directly modulates adipocyte signalling and endocrine function. Metformin activates p44/p42 MAP kinase and impairs leptin secretion unless p44/p42 MAP kinase is inhibited. This effect is reversible and is not caused by alterations in adipocyte differentiation. Furthermore, it is selective since there is no activation of stress kinase, PI 3-kinase, and JAK/STAT signalling pathways. Modulation of endocrine adipocyte function by metformin may be important in the regulation of energy homeostasis.

Glueck et al. 2001, Fruehwald-Schultes et al. 2002); however, in other studies, no effect on serum leptin was found (Guler et al. 2000, Mannucci et al. 2001, Uehara et al. 2001, Ciaraldi et al. 2002, Sivitz et al. 2003). Possible explanations for these discrepancies may be the length of treatment and the study population, with obese people showing a decrease in leptin levels after long-term treatment. A negative correlation of the length of metformin therapy with circulating leptin levels in this setting could possibly be accounted for by a direct subacute effect of this anti-diabetic drug on adipose tissue as described in this study.

In a previous study in rat white adipocytes, a negative influence of chronic metformin exposure on leptin secretion has also been reported (Mueller et al. 2000). As we show here, the direct metformin-induced impairment in leptin secretion is independent of changes in adipocyte morphology and differentiation. Furthermore, it is already evident after $24 \mathrm{~h}$ of treatment, and it is reversible. As was the case with activation of $\mathrm{p} 44 / \mathrm{p} 42$ MAP kinase, these observations point towards a selective signalling mechanism mediating these effects. In favour of this assumption, we found that inhibition of $\mathrm{p} 44 / \mathrm{p} 42$ MAP kinase signal- ling prevented the metformin-induced reduction in leptin secretion, thus suggesting an involvement of this important growth factor signalling intermediate in the modulation of endocrine adipocyte function.

In summary, our data show a direct selective interaction of metformin with adipocyte p44/p42 MAP kinase signalling and leptin secretion. They describe a potential molecular mechanism mediating this anorexigenic compound's effects on adipose tissue. Selective modulation of adipose tissue function could have important implications for therapeutic strategies of the insulin resistance syndrome.

\section{Acknowledgements}

We would like to thank M Schümann for expert help with the leptin radioimmunoassay.

\section{Funding}

This study was supported by grants from the Deutsche Forschungsgemeinschaft (K1 1131/2-1 and Kl 1131/2-2), 
German Diabetes Association, and Faculty grants of the University of Lübeck to J K.

\section{References}

Argaud D, Roth H, Wiernsperger N \& Leverve XM 1993 Metformin decreases gluconeogenesis by enhancing the pyruvate kinase flux in isolated rat hepatocytes. European Journal of Biochemistry 213 $1341-1348$.

Bailey CJ \& Turner RC 1996 Metformin. New England Journal of Medicine 334 574-579.

Bray GA \& Greenway FL 1999 Current and potential drugs for treatment of obesity. Endocrine Reviews 20 805-875.

Ciaraldi TP, Kong AP, Chu NV, Kim DD, Baxi S, Loviscach M, Plodkowski R, Reitz R, Caulfield M, Mudaliar S \& Henry RR 2002 Regulation of glucose transport and insulin signalling by troglitazone or metformin in adipose tissue of type 2 diabetic subjects. Diabetes $\mathbf{5 1} 30-36$.

Danforth E Jr \& Himms-Hagen JH 1997 Obesity and diabetes and the beta-3 adrenergic receptor. European Journal of Endocrinology 136 362-365.

DeFronzo RA \& Goodman AM 1995 Efficacy of metformin in patients with non-insulin-dependent diabetes mellitus. The Multicenter Metformin Study Group. New England Journal of Medicine 333 541-549.

DeFronzo RA, Barzilai N \& Simonson DC 1991 Mechanism of metformin action in obese and lean noninsulin-dependent diabetic subjects. Journal of Clinical Endocrinology and Metabolism 73 1294-1301.

Dominguez LJ, Davidoff AJ, Srinivas PR, Standley PR, Walsh MF \& Sowers JR 1996 Effects of metformin on tyrosine kinase activity, glucose transport, and intracellular calcium in rat vascular smooth muscle. Endocrinology 137 113-121.

Fogelholm M, Valve R, Kukkonen-Harjula K, Nenonen A, Hakkarainen V, Laakso M \& Uusitupa M 1998 Additive effects of the mutations in the beta3-adrenergic receptor and uncoupling protein-1 genes on weight loss and weight maintenance in Finnish women. Journal of Clinical Endocrinology and Metabolism 83 4246-4250.

Freemark M \& Bursey D 2001 The effects of metformin on body mass index and glucose tolerance in obese adolescents with fasting hyperinsulinemia and a family history of type 2 diabetes. Pediatrics 107 E55.

Friedman JM 2002 The function of leptin in nutrition, weight, and physiology. Nutrition Reviews 60 S1-S14

Friedman JM \& Halaas JL 1998 Leptin and the regulation of body weight in mammals. Nature $395763-770$.

Fruehwald-Schultes B, Oltmanns KM, Toschek B, Sopke S, Kern W, Born J, Fehm HL \& Peters A 2002 Short-term treatment with metformin decreases serum leptin concentration without affecting body weight and body fat content in normal-weight healthy men. Metabolism 51 531-536.

Fumeron F, Durack-Bown I, Betoulle D, Cassard-Doulcier AM, Tuzet S, Bouillaud F, Melchior JC, Ricquier D \& Apfelbaum M 1996 Polymorphisms of uncoupling protein (UCP) and beta 3 adrenoreceptor genes in obese people submitted to a low calorie diet. International Journal of Obesity and Related Metabolic Disorders 20 1051-1054.

Glueck CJ, Fontaine RN, Wang P, Subbiah MT, Weber K, Illig E, Streicher P, Sieve-Smith L, Tracy TM, Lang JE \& McCullough P 2001 Metformin reduces weight, centripetal obesity, insulin, leptin, and low-density lipoprotein cholesterol in nondiabetic, morbidly obese subjects with body mass index greater than 30. Metabolism $\mathbf{5 0}$ 856-861.

Guler S, Cakir B, Demirbas B, Gursoy G, Serter R \& Aral Y 2000 Leptin concentrations are related to glycaemic control, but do not change with short-term oral antidiabetic therapy in female patients with type 2 diabetes mellitus. Diabetes, Obesity and Metabolism 2 313-316.
Hawley SA, Gadalla AE, Olsen GS \& Hardie DG 2002 The antidiabetic drug metformin activates the AMP-activated protein kinase cascade via an adenine nucleotide-independent mechanism. Diabetes 51 2420-2425.

Kirpichnikov D, McFarlane SI \& Sowers JR 2002 Metformin: an update. Annals of Internal Medicine 137 25-33.

Klaus S 2004 Adipose tissue as a regulator of energy balance. Current Drug Targets 5 241-250.

Klein J, Fasshauer M, Ito M, Lowell BB, Benito M \& Kahn CR 1999 Beta(3)-adrenergic stimulation differentially inhibits insulin signalling and decreases insulin-induced glucose uptake in brown adipocytes. Journal of Biological Chemistry 274 34795-34802.

Klein J, Fasshauer M, Benito M \& Kahn CR 2000 Insulin and the beta3-adrenoceptor differentially regulate uncoupling protein-1 expression. Molecular Endocrinology 14 764-773.

Klein J, Fasshauer M, Klein HH, Benito M \& Kahn CR 2002 Novel adipocyte lines from brown fat: a model system for the study of differentiation, energy metabolism, and insulin action. Bioessays 24 382-388.

Kraus D, Fasshauer M, Ott V, Meier B, Jost M, Klein HH \& Klein J 2002 Leptin secretion and negative autocrine crosstalk with insulin in brown adipocytes. Journal of Endocrinology 175 185-191.

Kumar N \& Dey CS 2002 Metformin enhances insulin signalling in insulin-dependent and -independent pathways in insulin resistant muscle cells. British Journal of Pharmacology 137 329-336.

Large V \& Beylot M 1999 Modifications of citric acid cycle activity and gluconeogenesis in streptozotocin-induced diabetes and effects of metformin. Diabetes 48 1251-1257.

Lowell BB \& Flier JS 1997 Brown adipose tissue, beta 3-adrenergic receptors, and obesity. Annual Review of Medicine 48 307-316.

Lowell BB \& Bachman ES 2003 Beta-adrenergic receptors, diet-induced thermogenesis, and obesity. Journal of Biological Chemistry 278 29385-29388.

Mannucci E, Ognibene A, Cremasco F, Bardini G, Mencucci A, Pierazzuoli E, Ciani S, Messeri G \& Rotella CM 2001 Effect of metformin on glucagon-like peptide 1 (GLP-1) and leptin levels in obese nondiabetic subjects. Diabetes Care 24 489-494.

Matthaei S, Hamann A, Klein HH, Benecke H, Kreymann G, Flier JS \& Greten H 1991 Association of metformin's effect to increase insulin-stimulated glucose transport with potentiation of insulin-induced translocation of glucose transporters from intracellular pool to plasma membrane in rat adipocytes. Diabetes 40 850-857.

Matthaei S, Reibold JP, Hamann A, Benecke H, Haring HU, Greten $\mathrm{H} \&$ Klein HH 1993 In vivo metformin treatment ameliorates insulin resistance: evidence for potentiation of insulin-induced translocation and increased functional activity of glucose transporters in obese (fa/fa) Zucker rat adipocytes. Endocrinology 133 304-311.

Matthaei S, Stumvoll M, Kellerer M \& Haring HU 2000 Pathophysiology and pharmacological treatment of insulin resistance. Endocrine Reviews 21 585-618.

Meuillet EJ, Wiernsperger N, Mania-Farnell B, Hubert P \& Cremel G 1999 Metformin modulates insulin receptor signalling in normal and cholesterol-treated human hepatoma cells (HepG2). European Journal of Pharmacology 377 241-252.

Mueller WM, Stanhope KL, Gregoire F, Evans JL \& Havel PJ 2000 Effects of metformin and vanadium on leptin secretion from cultured rat adipocytes. Obesity Research 8 530-539.

Oberkofler H, Dallinger G, Liu YM, Hell E, Krempler F \& Patsch W 1997 Uncoupling protein gene: quantification of expression levels in adipose tissues of obese and non-obese humans. Journal of Lipid Research 38 2125-2133.

Pedersen O, Nielsen O, Bak J, Richelsen B, Beck-Nielsen H \& Sorensen N 1989 The effects of metformin on adipocyte insulin action and metabolic control in obese subjects with type 2 diabetes. Diabetic Medicine 6 249-256.

Porras A, Alvarez AM, Valladares A \& Benito M 1998 p42/p44 mitogen-activated protein kinases activation is required for the 
insulin-like growth factor-I/insulin induced proliferation, but inhibits differentiation, in rat fetal brown adipocytes. Molecular Endocrinology 12 825-834.

Radziuk J, Zhang Z, Wiernsperger N \& Pye S 1997 Effects of metformin on lactate uptake and gluconeogenesis in the perfused rat liver. Diabetes 46 1406-1413.

Rajala MW \& Scherer PE 2003 Minireview: The adipocyte - at the crossroads of energy homeostasis, inflammation, and atherosclerosis. Endocrinology 144 3765-3773.

Rouru J, Koulu M, Peltonen J, Santti E, Hanninen V, Pesonen U \& Huupponen R 1995 Effects of metformin treatment on glucose transporter proteins in subcellular fractions of skeletal muscle in (fa/fa) Zucker rats. British Journal of Pharmacology 115 1182-1187.

Sarabia V, Lam L, Burdett E, Leiter LA \& Klip A 1992 Glucose transport in human skeletal muscle cells in culture. Stimulation by insulin and metformin. Journal of Clinical Investigation 90 1386-1395.

Sivitz WI, Wayson SM, Bayless ML, Larson LF, Sinkey C, Bar RS \& Haynes WG 2003 Leptin and body fat in type 2 diabetes and monodrug therapy. Journal of Clinical Endocrinology and Metabolism $\mathbf{8 8}$ 1543-1553.

Spiegelman BM \& Flier JS 2001 Obesity and the regulation of energy balance. Cell 104 531-543.

Stith BJ, Goalstone ML, Espinoza R, Mossel C, Roberts D \& Wiernsperger N 1996 The antidiabetic drug metformin elevates receptor tyrosine kinase activity and inositol 1,4,5-trisphosphate mass in Xenopus oocytes. Endocrinology 137 2990-2999.

Stith BJ, Woronoff K \& Wiernsperger N 1998 Stimulation of the intracellular portion of the human insulin receptor by the antidiabetic drug metformin. Biochemical Pharmacology 55 533-536.

Tiraby C \& Langin D 2003 Conversion from white to brown adipocytes: a strategy for the control of fat mass? Trends in Endocrinology and Metabolism 14 439-441.
Tiraby C, Tavernier G, Lefort C, Larrouy D, Bouillaud F, Ricquier D \& Langin D 2003 Acquirement of brown fat cell features by human white adipocytes. Journal of Biological Chemistry 278 33370-33376.

Uehara MH, Kohlmann NE, Zanella MT \& Ferreira SR 2001 Metabolic and haemodynamic effects of metformin in patients with type 2 diabetes mellitus and hypertension. Diabetes, Obesity and Metabolism 3 319-325.

Valve R, Heikkinen S, Rissanen A, Laakso M \& Uusitupa M 1998 Synergistic effect of polymorphisms in uncoupling protein 1 and beta3-adrenergic receptor genes on basal metabolic rate in obese Finns [see comments]. Diabetologia 41 357-361.

Wiernsperger NF \& Bailey CJ 1999 The antihyperglycaemic effect of metformin: therapeutic and cellular mechanisms. Drugs 58 (Suppl 1) 31-39; discussion 75-82.

Yang X, Enerback S \& Smith U 2003 Reduced expression of FOXC2 and brown adipogenic genes in human subjects with insulin resistance. Obesity Research 11 1182-1191.

Yki-Jarvinen H, Nikkila K \& Makimattila S 1999 Metformin prevents weight gain by reducing dietary intake during insulin therapy in patients with type 2 diabetes mellitus. Drugs 58 (Suppl 1) 53-54; discussion 75-82.

Zhou G, Myers R, Li Y, Chen Y, Shen X, Fenyk-Melody J, Wu M, Ventre J, Doebber T, Fujii N, Musi N, Hirshman MF, Goodyear LJ \& Moller DE 2001 Role of AMP-activated protein kinase in mechanism of metformin action. Journal of Clinical Investigation 108 1167-1174.

Received 30 June 2004

Accepted 23 July 2004

Made available online as an Accepted Preprint 10 August 2004 